Discussion Paper No. 14-030

Bigger Cakes with Less Ingredients?

A Comparison of

Material Use of the World Economy

Frank Pothen and Michael Schymura

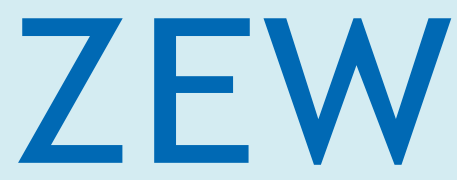

Zentrum für Europäische Wirtschaftsforschung $\mathrm{GmbH}$

Centre for European

Economic Research 
Discussion Paper No. 14-030

\title{
Bigger Cakes with Less Ingredients? A Comparison of Material Use of the World Economy
}

\author{
Frank Pothen and Michael Schymura
}

Download this ZEW Discussion Paper from our ftp server:

http://ftp.zew.de/pub/zew-docs/dp/dp14031.pdf

Die Discussion Papers dienen einer möglichst schnellen Verbreitung von neueren Forschungsarbeiten des ZEW. Die Beiträge liegen in alleiniger Verantwortung der Autoren und stellen nicht notwendigerweise die Meinung des ZEW dar.

Discussion Papers are intended to make results of ZEW research promptly available to other economists in order to encourage discussion and suggestions for revisions. The authors are solely responsible for the contents which do not necessarily represent the opinion of the ZEW. 


\section{BIGGER CAKES WITH LESS INGREDIENTS?}

\section{A comparison of material use of the world economy}

Frank Pothen, and Michael Schymura ${ }^{\dagger}$

- May 5, $2014-$

\section{Summary}

The amount of materials used worldwide in production and consumption increased by 56 per cent from 1995 to 2008 . Using an index decomposition analysis based on the logarithmic mean divisia index, we investigate the drivers of material use, both on a global and a country scale. We exploit a panel dataset of 40 countries, accounting for 75 per cent of worldwide material extraction and 88 per cent of GDP, from 1995 to 2008. The results show that economic growth and structural change towards material-intensive countries explain most of the growth in global material use. Slight gains in material efficiency and falling importance of material-intensive sectors have decelerating effects. The country-level analysis reveals substantial heterogeneity. Some nations exhibit stable or falling material use, while it increases notably in most countries. Improving material efficiency is able to dampen growth of material use in important industrializing nations like China or India.

Keywords: Material use, Index decomposition analysis, Economic growth JEL-Classification: Q0, Q40, Q42, Q48

\footnotetext{
${ }^{*}$ Centre for European Economic Research (ZEW), E-mail: pothen@zew.de

${ }^{\dagger}$ Centre for European Economic Research (ZEW), E-mail: schymura@zew.de.
} 


\section{INTRODUCTION}

In 1995, industries worldwide extracted 48 billion (metric) tons of raw materials from nature to use them in production processes or to consume them. This number rose to 68.7 billion tons by 2008 . If unused extraction like overburden from mining is considered, humanity additionally withdrew approximately 41.3 billion tons in 2008 alone. Raw material extraction grew unequally in this time period. China's boosting importance is particularly striking. Its domestic material extraction more than doubled from 7.9 billion tons in 1995 to 18.1 billion tons in 2008. China also expanded its raw material supply in relative terms. While the People's Republic accounted for 16.4 per cent of worldwide material extraction in 1995, it supplied 26.4 per cent of total extraction in 2008 (calculations based on Dietzenbacher et al., 2013). 1

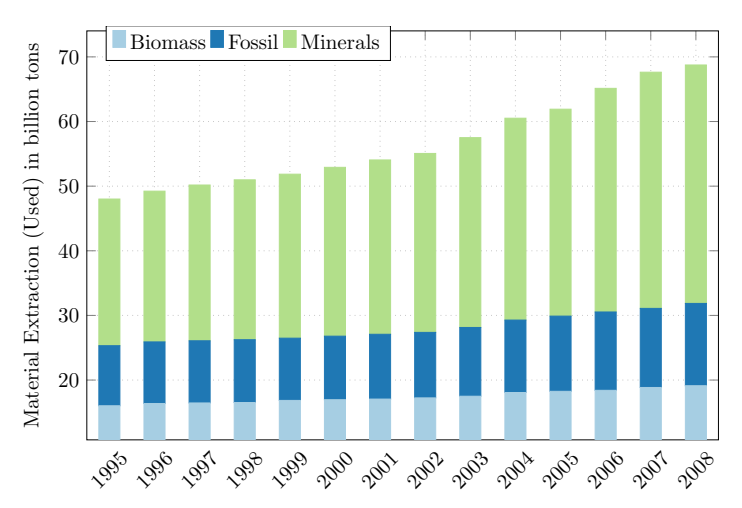

(1.1) Global Extraction

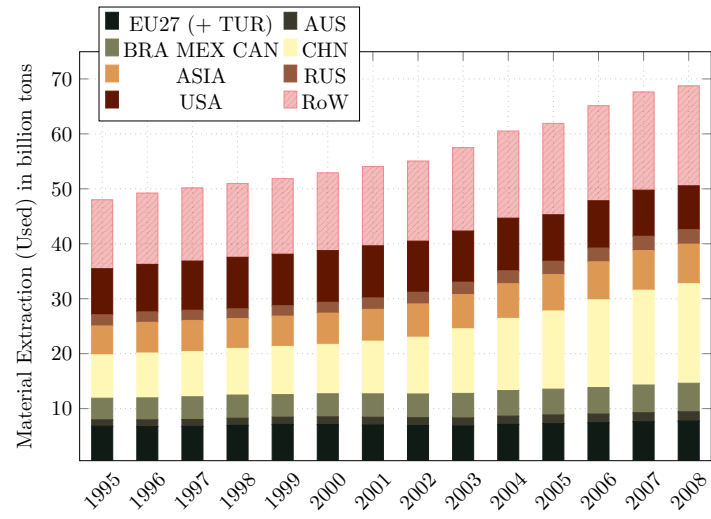

(1.2) Regional Distribution

Figure 1: Resource extraction and its regional distribution; Data: Dietzenbacher et al. (2013)

Material use is closely connected to global and local environmental phenomena, from climate change over deforestation to losses in biodiversity. The European Union made resource efficiency a major topic in its policies and it is now a key priority for policymakers across Europe. The European Union emphasized resource efficiency as one of seven flagship initiatives in its Europe 2020 strategy for smart, sustainable and inclusive growth (European Environment Agency, 2011).

Our aim is to disentangle the drivers of material use worldwide. We separate the influence that technical change, structural change and overall economic growth exert on material use. We define material use as the amount of materials that are employed directly by sectors and final consumers, both domestic and imported. It comprises the use of biomass, fossil fuels, and minerals including metals. In accordance with the literature, we do not consider the use of air and water. This definition corresponds to direct material consumption in the material flow analysis literature (Fischer-Kowalski et al., 2011). ${ }^{2}$ We investigate material use rather than extraction

\footnotetext{
${ }^{1}$ All figures on resource extraction exploit the whole environmental satellite accounts of the World Input-Output Database including information on countries not included in the main database, aggregated in a "Rest of World" block. The further analysis rely on data for the 40 countries with detailed information. Those 40 countries account for $75 \%$ of resource extraction and $88 \%$ of economic output.

${ }^{2}$ We denote our measure material use to emphasize that a large share of materials is used in the production process and not consumed directly as final demand.
} 
for two reasons. Firstly, demand for raw materials is derived from production and consumption decisions. Secondly, regional extraction patterns reflect costs largely determined by geological or climatic conditions.

We exploit the World Input-Output Database (WIOD, Dietzenbacher et al., 2013), containing harmonized input-output tables for 40 major economies and 35 sectors as well as data on material extraction. Based on the WIOD, we construct a panel of direct material use taking into account both domestically extracted and imported materials. Subsequently, we use an index decomposition analysis (IDA, Ang and Zhang, 2000; Ang et al., 2010; Voigt et al., 2014) to investigate trends in material use. The decomposition approach applied in this study allows us to analyze both national and global developments.

A number of studies investigate drivers of material use empirically. They can be divided into three groups according to the employed methodology. The first group is based on index decomposition analysis applied to country-level data. Hoffrén et al. (2000) present an early example of this literature for the case of Finland. Hashimoto et al. (2008) decompose the material intensity of Japan from 1995 to 2002 and find that changes in demand structure and efficiency gains in production are the most important drivers of falling material intensity in this period.

Other studies on material use are based on structural decomposition analysis (SDA). Pablo Muñoz and Hubacek (2008) investigate Chile's material use from 1986 to 1996 . They measure material use as domestic material intensity (DMI), which equals the sum of domestically extracted and imported materials. Thus, their measure also includes materials extracted for exports. Pablo Muñoz and Hubacek (2008) find that overall economic growth and increased exports explain most of Chile's raising DMI. Falling ore grades (the share of metals in a unit of ore) in copper mining contribute as well. Another study of a raw material exporting country is conducted by Wood et al. (2009), decomposing the growth of Australian material use. Similar to Pablo Muñoz and Hubacek (2008), they find economic growth and increasing exports to be particularly important. Contrary to the Chilean case, they identify small growth of material efficiency. Weinzettel and Kovanda (2011) compare the raw material consumption (RMC) in the Czech Republic in 2000 and 2007 using an SDA. RMC is a consumption-based indicator, measuring the raw material extraction implied by final consumption. They find that technology, including both material intensities and economic structure, improved between these years, but did not compensate for the growing demand in the Czech Republic. All previous studies relying on index decomposition analysis or structural decomposition analysis are carried out at the level of single countries. To our best knowledge, we present the first multi-country IDA of material use.

A third group of papers employs econometric techniques to examine the drivers of material use. Steinberger et al. (2010) use cross-sectional data of 175 nations in 2000. They find that income is an important driver for material use, but with notable differences between types of materials. The use of biomass exhibits a small income elasticity, but the use of minerals and fossil fuels grows proportionally to income. Wiedmann et al. (2013) investigate factors explaining the material footprint, a consumption based indicator, of 186 countries in 2008. Their regressions also show that income is important. For each 10 per cent increase in income, the material footprint grows by 6 per cent. Steger and Bleischwitz (2011) use panel data to assess 
drivers of material use and material intensities in the EU from 1980 to 2000 (EU 15) and between 1992 and 2000 (EU 25). Their study is the only one known to us which employs panel data, rendering their approach highly complementary to ours. While Steger and Bleischwitz (2011) pool their data and consider a large variety of potential explanatory variables, we focus on developments over time while restricting our analysis to a limited number of explanatory factors. Steger and Bleischwitz (2011) find energy consumption, construction activities, and the length of transportation networks (e.g. roads, rail networks) to be important drivers of both endogenous variables.

Our contribution is related to the index decomposition literature and introduces three novel features. Firstly, we are able to exploit a consistent and harmonized dataset containing detailed information on economic activity and environmental impacts. It combines a global scale with a high sectoral resolution. Secondly, we are able to observe changes in material use over a long and merely current period from 1995 to 2008. And thirdly, we are able to aggregate economic output and material use of 40 major economies into a global aggregate, allowing us to distinguish between within-country and between-country structural change. This adds an additional dimension to the three drivers of material disentangled on the country level: Overall economic growth, structural change in the sectoral composition of an economy, and within-sector intensity changes.

Our findings suggest that economic growth is the main driver for the development of global material use. At an aggregate level, there was no "decoupling" of economic growth and material use. There is, however, large heterogeneity in the development of individual countries as well as sectors. Some nations, for example, exhibited economic growth combined with falling material use.

\section{DATA AND DESCRIPTIVES}

\subsection{The WIOD Database}

The main data source for our analysis is the newly released World Input-Output Database (Dietzenbacher et al., 2013) ${ }^{3}$ The WIOD database is built on national accounts data and was developed within the 7th Framework Programme of the European Commission 4 The relevant information for this study is part of the Social Economic Accounts (SEA), the World Input-Output tables containing information on trade flows and intermediate inputs, as well as the material extraction data provided as satellite accounts accompanying the input-output tables. The measure of sectoral economic activity relevant for our analysis is gross output $(G O)$ which is expressed in monetary units in basic 1995 prices and converted to million US\$ (1995) using market exchange rates. The WIOD database has two main advantages. Firstly, throughout the data collection effort, harmonization procedures were applied to ensure international comparability of the basic data. This ensures data quality and minimizes the risk of measurement errors. Secondly, WIOD includes sectoral price

\footnotetext{
${ }^{3}$ The WIOD database and all satellite accounts are available at http://www.wiod.org. In this paper, we use data released in April 2012.

${ }^{4}$ The WIOD project has been funded by the European Commission, Research Directorate General as part of the 7th Framework Programme, Theme 8: Socio-Economic Sciences and Humanities. Grant Agreement no: 225281.
} 
deflators, the use of which allows to retain important information on the heterogeneity of the sectors with respect to price developments. This represents an improvement over the use of aggregate national price deflators. A complete list of the 34 sectors is presented in Table 1 in the appendix. $5^{5}$

The structure of the WIOD hence allows us to address the research questions outlined above by focusing on many heterogeneous countries over a fairly long time span. This is an improvement over the previously available literature which was more limited either geographically or with respect to the time dimension.

The WIOD contains information about material extraction based on the Global Material Flow Database (SERI, 2013) and Eurostat's Material Flow Accounts. Twelve types of extraction are distinguished, which can be consolidated into biomass, fossil fuels, and minerals. Extraction is measured in 1000 (metric) tons (kt) and provided both for used and unused extraction. Used extraction enters the economic system, while unused extraction is of no value for production and consumption (e.g. overburden). Due to substantially higher data quality, we confine our investigation to used extraction.

Material extraction is allocated to two sectors in the World Input-Output database. The sector AtB (Agriculture, hunting, forestry and fishing) is assumed to extract all biomass, the sector $\mathrm{C}$ (Mining and quarrying) is responsible for the extraction of fossil fuels and minerals. Table 2 in the appendix presents the types of materials and the corresponding sectors.

To identify the material use, we first sum up the materials extracted by each extraction sector $i x=\{A t B, C\}$. Let $E_{i x, j, t}$ denote the material extraction by sector $i x$ in region $j$ and year $t$. Since WIOD only distinguishes two extraction sectors, differentiating more material flows is not possible.

We assume that the extraction sectors' prices are identical irrespectively of whom they sell their output to. That implies that a dollar of purchases from an extraction sector always contains the same amount of materials $\sqrt{6} \beta_{i x, k, i, j, t}^{i}$ denotes the share that sector $i$ in region $j$ uses from the total output of extraction sector $i x$ in region $k$ and is computed according to equation (1), where $I I_{i x, k, i, j, t}$ is the intermediate input from extraction sector $i x$ in $k$ to sector $i$ in $j$.

$$
\beta_{i x, k, i, j, t}^{i}=\frac{I I_{i x, k, i, j, t}}{G O_{i x, k, t}}
$$

\footnotetext{
${ }^{5}$ The countries in the database include all EU member states, other OECD member states including all the large developed countries, and the most important emerging economies including the BRIC countries (Brazil, Russia, India, China). All other countries are summarized in an aggregate region "Rest of the World" (RoW) which is only used, however, to complete the trade data. No SEAs are provided for this region. In addition to providing economic time series data for the period from 1995 to 2009 , WIOD contains several consistent satellite accounts with the same sectoral classification as the core dataset. The satellite accounts consist of socioeconomic data (i.e. skill types of labor, sectoral and total capital stocks) and, most important for our purpose, a rich set of environmental information, including materials extraction separated by sector and numerous material types (biomass, fossil, minerals etc.). We restrain our analysis to the period from 1995 to 2008 and thus exclude 2009, which is likely to be heavily distorted by the financial crisis.

6 Giljum et al. (2008) employ a similar procedure to allocate material extraction, but they limit material flow to a number of pre-defined processing sectors.
} 
Analogously, $\beta_{i x, k, j, t}^{f d}$ is the share that is consumed as final demand from region $j$ in sector $i x$ 's output. It is calculated according to equation (2), where $F D_{k, i x, j, t}$ is the aggregate final demand in region $j$ for goods of sector $i x$ in $k$.

$$
\beta_{i x, k, i, t}^{f d}=\frac{F D_{i x, k, j, t}}{G O_{i x, k, t}}
$$

To derive the material use of sectors $\left(M_{i, j, t}^{i}\right)$ and final demand $\left(M_{j, t}^{f d}\right)$, we add up their input of materials from all extraction sectors as presented in equations (3) and (4).

$$
\begin{aligned}
M_{i, j, t}^{i} & =\sum_{k, i x} \beta_{i x, k, i, j, t}^{i} E_{i x, k, t} \\
M_{j, t}^{f d} & =\sum_{k, i x} \beta_{i x, k, i, t}^{f d} E_{i x, k, t}
\end{aligned}
$$

Country $j$ 's overall material use $M_{j, t}$ is thus

$$
M_{j, t}=\sum_{i} M_{i, j, t}^{i}+M_{j, t}^{f d}
$$

\subsection{Country and sectoral descriptives}

From 1995 to 2008, material use of the 40 economies included in our sample increased by 56 per cent (see Figures 11.1 and 11.2). However, both figures present a very aggregated picture of global material use. It is aggregated with respect to two dimensions: sector-specific and country-specific developments. In this subsection, we undertake a first step towards a more fine-grained picture of sectoral and country heterogeneity.

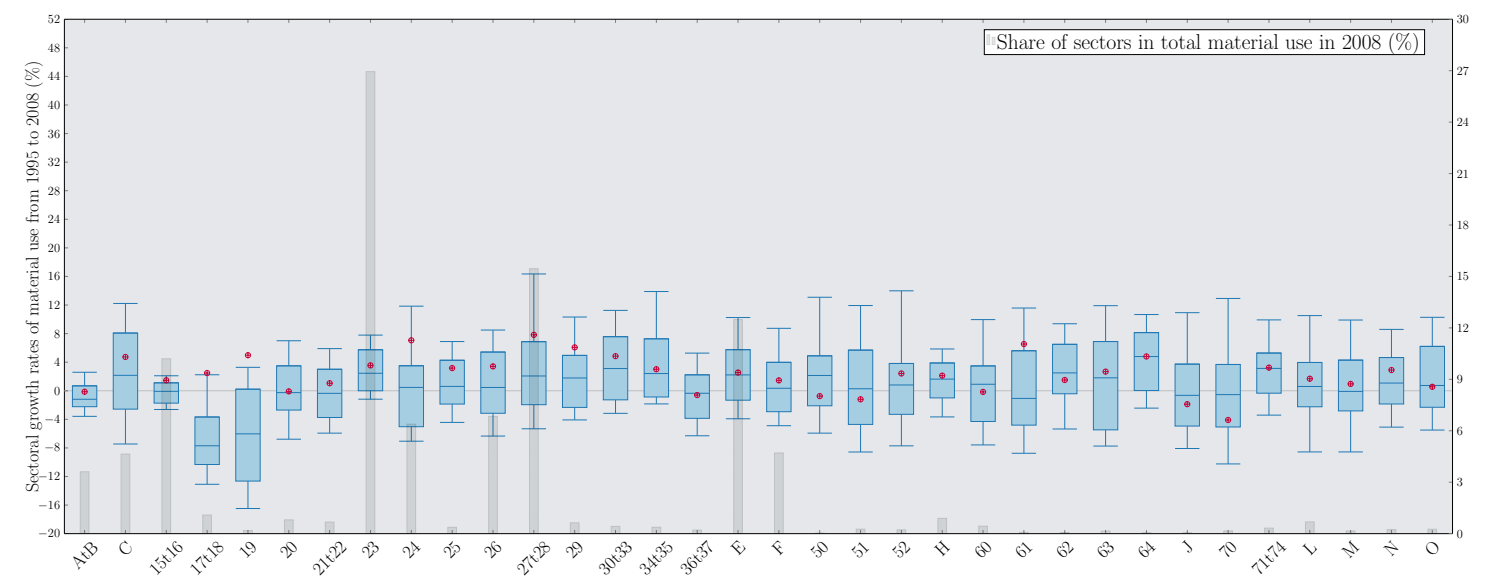

Figure 2: Boxplot sectors

The development of material use is the result of heterogeneous sectoral dynamics as indicated by the boxplots in figure 2. We calculate the average annual material use changes within our sample period for each sector in each country. Each boxplot in figure 2 depicts the heterogeneity of the sectoral changes across countries. The lower 
and upper whiskers represent the respective $10^{t h}$ and $90^{t h}$ percentile of the growth rate (in per cent). The lower bound of the box represents the $25^{t h}$ percentile in annual material use changes, the upper bound of the box represents the $75^{\text {th }}$ percentile. The median is indicated by the bar in the box and the red circle represents the weighted average material use change of the sector aggregated over the 40 countries in the sample. Additionally, the plot contains information on each sector's "weight", i.e. the share of material use in total material use in 2008 (the grey bars). A comparison of the median and the weighted average value allows to gain important insights on the country distribution with respect to material intensity development.

A mean growth rate above the median indicates that countries with a high share of gross output within a sector performed worse than the majority of other countries. Such a large divergence between weighted mean and median change in material intensity occurs in sectors with a relatively poor overall performance regarding material intensity reduction, such as mining and quarrying $(\mathrm{C})$, coke, refined petroleum and nuclear fuel (23), chemicals and chemical products (24), other non-metallic mineral products (26), basic metals and fabricated metal products (27t28), electricity, gas and water supply (E) and construction (F). Each of these sectors is of major importance with shares between 6 and 30 per cent in total material use.

The foremost reason for the divergence between weighted mean and median change is the (economic) rise of China. China has a high output share but performed relatively poorly with respect to material use reductions in all sectors mentioned above. China's share in material use in the mining and quarrying sector was 23 per cent in 1995 and rose to 51 per cent in 2008 . The opposite can be observed for the United States, where the share decreased from 30 per cent to 18 per cent. This development is even more pronounced in the basic metals and fabricated metal products sector. The Chinese share increased from 36 to 64 per cent while the US share fell from 10 to 2.5 per cent.

Conversely, four sectors show substantially lower mean than median growth rates. In this case, countries with high gross output and material use shares presumably performed better than the majority. The four sectors with the largest difference in this regard are sale, maintenance and repair of motor vehicles (50), wholesale trade and commission trade (51), financial intermediation ( $\mathrm{J})$ and real estate services (70). In these sectors, countries having gross output shares of more than $20 \%$ in the respective aggregated "global" sector performed far better in terms of material use than the global average. However, all these sectors are service sectors and their share of total material use is almost negligible.

A second dimension of heterogeneity of changes in material use is country heterogeneity. Figure 3 shows the distribution of material use developments for all sectors within a given country. The boxplots are constructed in a manner analogous to those shown in Figure 2 and are based on the average annual material use growth rate over the time span from 1995 to 2008. Also in this case, if the weighted mean growth rate is above the median, this indicates that sectors with a high share of gross output within the specific country performed worse than the majority of other sectors and vice versa.

Similar to the sectoral analysis, we observe growing material use in most countries of our sample. With respect to the spread of material use developments across the sectors in each country, we observe large differences. Many countries - namely 
the Czech Republic, Germany, Denmark, the United Kingdom and Japan - have $75^{t h}$ percentiles below zero, i.e. most of the sectors actually reduced their material use. In various other countries, the distribution across sectors is clearly dominated by increases in material use. This observation is confirmed when looking at the median which is also positive for most economies.

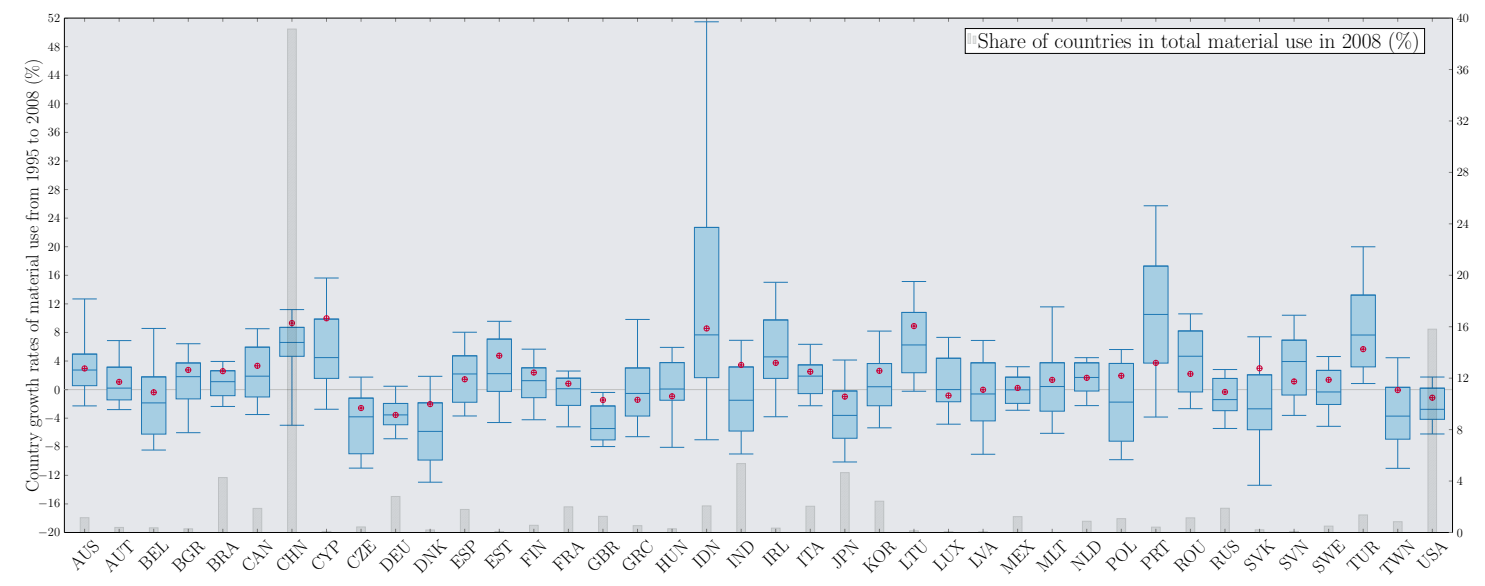

Figure 3: Boxplot countries

Figure 3 reveals that mean intensity growth is considerably greater than the median in some countries, i.e. large sectors did perform substantially worse than the majority in terms of material use development. Among these countries are India, the United States and, most importantly, China. What separates these countries is the fact that for the United States both the median as well as the mean are below the zero percent line, for India at least the median is below the zero per cent line and that for China both mean and median are positive. For some countries, the opposite applies with the most pronounced difference in Portugal, Greece, Slovenia and Turkey. In these cases, sectors with high gross output and material use shares performed better than the majority.

Heterogeneity in material use change is, in general, slightly more pronounced within sectors than within countries. The average difference between the 90 th and the 10th percentile is 14.5 for countries while it is 15.6 for the sectoral perspective. This indicates that conditions in a country have a stronger influence on the development of material use than conditions in a sector, implying a possible similarity of countries across the globe with respect to material use improvement options.

\section{The Mean Divisia Index Decomposition of Material Use}

While the descriptive analysis illustrates developments of material use across sectors and countries, it does not inform about the drivers behind the changes. We decompose material use to shed light on these issues, both at the aggregate and the country level.

The development of material use in the economy can be attributed to three different but equally relevant changes. First, material use is likely to increase when economic output rises and to decrease in times with low economic growth (activity effect). Second, material use can increase or decline as a result of changes of the sec- 
toral composition of an economy (structural effect). And third, overall material use changes may be driven by sectoral material intensity improvements or deterioration (intensity effect).7 The main purpose of this paper is to study the trends in material use in 40 economies and disentangle in detail the contributions from economic growth, structural changes in the economy, i.e. a shift to economic sectors which feature higher or lower material use, as well as the effects of improvements in material intensity within the sectors of an economy. Such a research question can be addressed using two broad categories of decomposition methodologies: approaches based on input-output analysis, called structural decomposition analysis (SDA), and disaggregation techniques which can be referred to as index decomposition analysis (IDA) and which are related to index number theory in economics. Ma and Stern (2008) summarize the main advantages and disadvantages of each approach.

We use an index decomposition approach (IDA) as described by Ang and Zhang (2000); Boyd and Roop (2004); Ang et al. (2010) and, more recently, by Choi and Ang (2012) or Voigt et al. (2014) for total, sectoral and national energy intensities and adjust this approach to analyze material use. We focus on the structural changes that affect the supply side of the economy (productive sectors) and thus exclude the private households.

Following Ang and Zhang (2000), we rely on multiplicative decomposition and use the "logarithmic mean divisia index" (LMDI-II) approach (Ang and Choi, 1997), 8

This methodology offers very important advantages: (1) it is zero-value robust (Ang et al., 1998, p. 491) and (2) it “yields perfect decomposition" (Ang et al., 1998, p. 495), i.e. no unexplained residual exists. The latter is a considerable advantage over the arithmetic mean divisia index, where the residual can be different from zero "when changes in the variables [...] are substantial", as in the case where the methodology is used in cross-country analyses (Ang and Zhang, 2000, p. 1165) ${ }^{9}$

\subsection{Country-Level IDA}

Our variable of interest is total material use of economy $j$ at time $t$. It is defined for each country as a weighted average of sectoral material intensities,

$$
M_{j, t}=\sum_{i} G O_{j, t} \frac{G O_{i, j, t}}{G O_{j, t}} \frac{M_{i, j, t}}{G O_{i, j, t}}=\sum_{i} G O_{j, t} S_{i, j, t} M I_{i, j, t}
$$

\footnotetext{
${ }^{7}$ The three different effects are similar to the terms scale effect, composition effect and technique effect coined by Grossman and Krueger (1991) in their analysis of the environmental impacts of the North American Free Trade Agreement (NAFTA).

${ }^{8}$ The difference between LMDI-I and LMDI-II can be found, beside a slightly different weight function, in the residual terms at the sub-category level. It means that, although LMDI-II provides decomposition results which are not perfect at the sub-category level, the sum of the residual terms for all the sub-categories is always zero so that LMDI-II still gives results which are perfect in decomposition. Similarly to the Office of Energy Efficiency and Renewable Energy of the United States we have decided to use the multiplicative LMDI-II approach (see Ang and Zhang, 1999, for further information on the differences between LMDI-I and LMDI-II).

${ }^{9}$ An alternative approach is additive decomposition. In addition, one could choose between alternative indicators, such as Paasche or Laspeyres indices. However, due to unexplained residuals during the decomposition procedure, which also arise for those types of indices, we prefer the logarithmic mean Divisia index.
} 
with the following notation:

- period: $t \in(1995,2008)$,

- sectors: $i=1, \ldots, 34$,

- countries: $j=1, \ldots, 40$,

- sectoral material use of sector $i$ in country $j$ and period $t: M_{i, j, t}$,

- material use of country $j$ in period $t: M_{j, t}=\sum_{i} M_{i, j, t}$,

- sectoral gross output of sector $i$ in country $j$ and period $t: G O_{i, j, t}$,

- gross output as a measure of economic activity of country $j$ in period $t: G O_{j, t}=$ $\sum_{i} G O_{i, j, t}$

- share of sector $i$ in total gross output of country $j$ in period $t: S_{i, j, t}=\frac{G O_{i, j, t}}{G O_{j, t}}$, and

- sectoral material intensity of sector $i$ in country $j$ and period $t: M I_{i, j, t}=\frac{M_{i, j, t}}{G O_{i, j, t}}$.

The multiplicative decomposition of change in total material use between the periods $t$ and $t+1$ is the product

$$
D_{T o t, j, t+1}=\frac{M_{j, t+1}}{M_{j, t}}=D_{A c t, j, t+1} D_{S t r, j, t+1} D_{I n t, j, t+1} .
$$

$D_{A c t, j, t+1}$ is the estimated impact of rising economic output on material use (activity effect) in period $t+1$. $D_{S t r, j, t+1}$ is the estimated impact of structural change on total material use in period $t+1 . D_{\text {Int }, j, t+1}$ is the estimated impact of changes in the sectoral material intensity (the inverse material efficiency) levels in period $t+1$ (intensity effect). The formulae for the log mean Divisia index decomposition are

$$
\begin{aligned}
D_{A c t, j, t+1} & =\exp \sum_{i} \frac{L\left(\omega_{i, j, t+1}, \omega_{i, j, t}\right)}{\sum_{i} L\left(\omega_{i, j, t+1}, \omega_{i, j, t}\right)} \ln \left(\frac{G O_{j, t+1}}{G O_{j, t}}\right), \\
D_{S t r, j, t+1} & =\exp \sum_{i} \frac{L\left(\omega_{i, j, t+1}, \omega_{i, j, t}\right)}{\sum_{i} L\left(\omega_{i, j, t+1}, \omega_{i, j, t}\right)} \ln \left(\frac{S_{i, j, t+1}}{S_{i, j, t}}\right), \\
D_{\text {Int }, j, t+1} & =\exp \sum_{i} \frac{L\left(\omega_{i, j, t+1}, \omega_{i, j, t}\right)}{\sum_{i} L\left(\omega_{i, j, t+1}, \omega_{i, j, t}\right)} \ln \left(\frac{M I_{i, j, t+1}}{M I_{i, j, t}}\right),
\end{aligned}
$$

where

$$
L\left(\omega_{i, j, t+1}, \omega_{i, j, t}\right)=\frac{\omega_{i, j, t+1}-\omega_{i, j, t}}{\ln \left(\frac{\omega_{i, j, t}}{\omega_{i, j, t+1}}\right)}
$$

is defined as the logarithmic mean, e.g. for the periods $t$ and $t+1$, and serves as a weighting scheme in the index decomposition framework (Ang and Zhang, 2000) and $\omega_{i, j, t}$ is the sectoral share of material use within a given country, $\omega_{i, j, t}=\frac{M_{i, j, t}}{M_{j, t}}$. As proposed by Ang and Liu (2007), we use chaining decomposition, i.e. the specific annual values are computed on a rolling basis (from 1995 to 1996, from 1996 to 1997 etc.) where the value for 1995 is set equal to 1 . These results are "chained" to obtain a time series from 1995 to 2008. 


\subsection{Global IDA}

The approach outlined in the previous subsection can be extended in order to conduct an index decomposition analysis at the global level. Therefore, we define global (aggregate) total material use at time $t$,

$$
M_{t}=\sum_{j} \sum_{i} G O_{t} \frac{G O_{j, t}}{G O_{t}} \frac{G O_{i, j, t}}{G O_{j, t}} \frac{M_{i, j, t}}{G O_{i, j, t}}=\sum_{j} \sum_{i} G O_{t} S_{j, t} S_{i, j, t} M I_{i, j, t}
$$

with the additional notation:

- global gross output in period $t: G O_{t}=\sum_{j} G O_{j, t}$,

- global material use in period $t: M_{t}=\sum_{j} M_{j, t}$,

- total global gross output in period $t: G O_{t}=\sum_{j} G O_{j, t}$, and

- share of country $j$ in total global gross output in period $t: S_{j, t}=\frac{G O_{j, t}}{G O_{t}}$.

This enables us to perform a four factor decomposition at the global level which is described analogously to equation 7 .

$$
D_{T o t, t+1}=\frac{M_{t+1}}{M_{t}}=D_{A c t, t+1} D_{b S t r, t+1} D_{w S t r, t+1} D_{\text {Int }, t+1} .
$$

In this case, we distinguish two aspects of structural change, a between-country structural effect, $D_{b S t r, t+1}$, and a within-country structural effect, $D_{w S t r, t+1}$. An increase of the former effect describes a shift of the global economy toward more materialintensive countries. An increase in the latter effect denotes a shift toward more material-intensive sectors within the countries of our sample. The global intensity effect, $D_{\text {Int }, t+1}$, describes the overall material intensity change aggregated over each sector and each country and $D_{A c t, t+1}$ describes the overall increase in economic output (activity effect). The corresponding formulae for the log mean divisia index decomposition are

$$
\begin{aligned}
D_{A c t, t+1} & =\exp \sum_{j} \sum_{i} \frac{L\left(\tilde{\omega}_{i, j, t+1} \sum_{i} \sum_{i, j, t}\right)}{L\left(\tilde{\omega}_{i, j, t+1,}, \tilde{\omega}_{i, j, t}\right)} \ln \left(\frac{G O_{t+1}}{G O_{t}}\right), \\
D_{b S t r, t+1} & =\exp \sum_{j} \sum_{i} \frac{L\left(\tilde{\omega}_{i, j, t+1}, \tilde{\omega}_{i, j, t}\right)}{\sum_{j} \sum_{i} L\left(\tilde{\omega}_{i, j, t+1}, \tilde{\omega}_{i, j, t}\right)} \ln \left(\frac{S_{j, t+1}}{S_{j, t}}\right), \\
D_{w S t r, t+1} & =\exp \sum_{j} \sum_{i} \frac{L\left(\tilde{\omega}_{i, j, t+1}, \tilde{\omega}_{i, j, t}\right)}{\sum_{j} \sum_{i} L\left(\tilde{\omega}_{i, j, t+1}, \tilde{\omega}_{i, j, t}\right)} \ln \left(\frac{S_{i, j, t+1}}{S_{i, j, t}}\right), \\
D_{I n t, t+1} & =\exp \sum_{j} \sum_{i} \frac{L\left(\tilde{\omega}_{i, j, t+1}, \tilde{\omega}_{i, j, t}\right)}{\sum_{j} \sum_{i} L\left(\tilde{\omega}_{i, j, t+1}, \tilde{\omega}_{i, j, t}\right)} \ln \left(\frac{M I_{i, j, t+1}}{M I_{i, j, t}}\right) .
\end{aligned}
$$

The logarithmic mean $L\left(\tilde{\omega}_{i, j, t+1}, \tilde{\omega}_{i, j, t}\right)$ is defined analogously to equation 11, but $\omega_{i, j, t}$ has to be replaced by the more fine-grained parameter $\tilde{\omega}_{i, j, t}$ describing the share of material of each country and sector within global aggregate material use, $\tilde{\omega}_{i, j, t}=$ $\frac{M_{i, j, t}}{M_{t}}$. Also in this case we apply chaining decomposition.

The rest of this paper compares the development of the respective components over time. By looking at these three variables, we assess their relative weights on 
material use developments. Following the analysis of the specific country trends to highlight region-specific dynamics (subsection 4.1), we compare those to the four factor decomposition at the global level (subsection 4.2).

\section{RESUlts}

In this section, we perform the index decomposition for the individual countries. Figure 4 plots the annual average growth rate of gross output against the annual average growth rates of material use (both in per cent) between 1995 and 2008. The dotted lines represent the world average for both. Countries which performed best are located in the lower right corner (implying above-average economic growth and below-average rise in material use) and countries which performed worst are located in the upper left corner (implying below-average economic growth and above-average growth in material use). After performing the index decomposition analysis for all

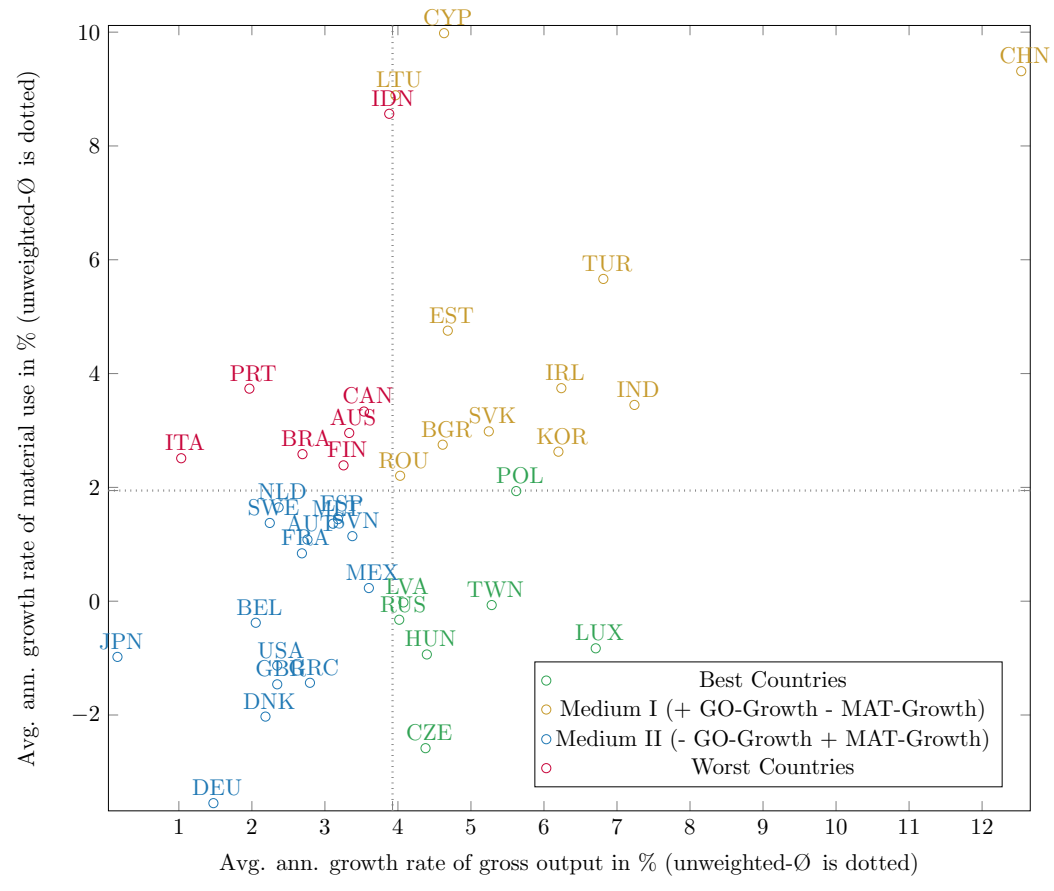

Figure 4: Gross output and material use growth

countries, we used Figure 4 to identify four country groups. Our summary of the results will be brief but we take a moment to address some country-specific peculiarities and refer the reader to the work of authors who delved into more detail.

\subsection{Country-specific results}

Best Performers All countries exhibiting above-average gross output growth and material use growing below average until 2008 are classified as best performers. Most best performers are eastern European countries. The group includes a large materials exporter (Russia), a small western European country (Luxembourg), and an important Asian country (Taiwan). Figures 55.1 to 55.7 display the country-level IDAs for the best performers. 
All graphs displaying the results of the index decomposition analyses can be interpreted analogously. The total effect (red line) is the change of material use relative to 1995. In the Czech Republic, for example, material use is some 14.6 per cent larger in 2008 than it was in 1995. The other lines correspond to the three components into which we decompose the total effect. They are measured relative to 1995 as well. An activity effect (dashed blue line) of greater than one means that economic growth drove material use above 1995 levels. If the structural effect is above one, sectoral composition shifted towards material-intensive sectors. An intensity effect (light blue line) of greater than one implies that sectors used materials more intensively (i.e. material efficiency fell). The total effect equals the product of the three effects.

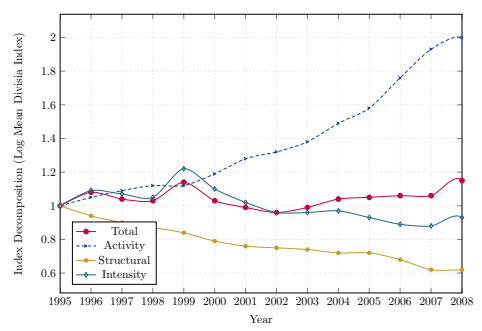

(5.1) Czech Republic

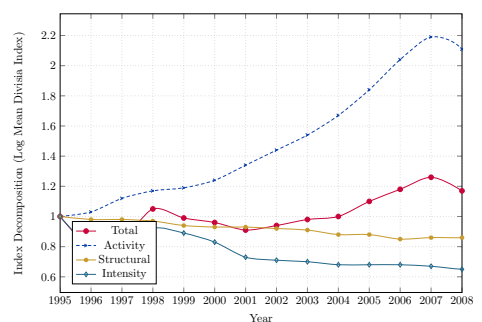

(5.4) Latvia

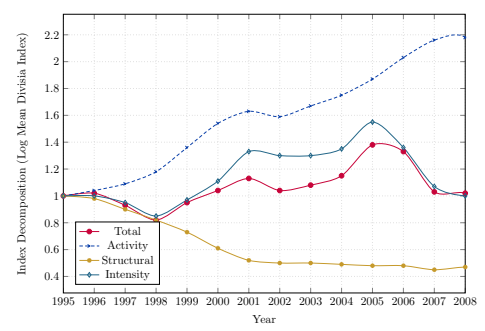

(5.2) Hungary

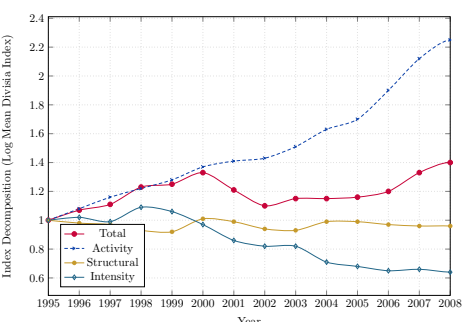

(5.5) Poland

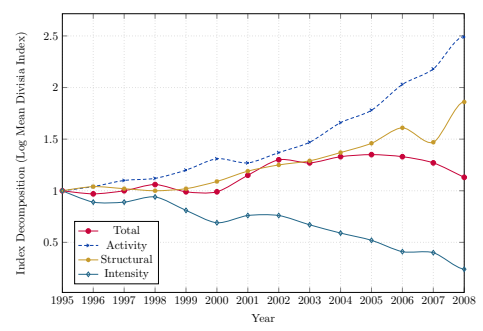

(5.7) Taiwan

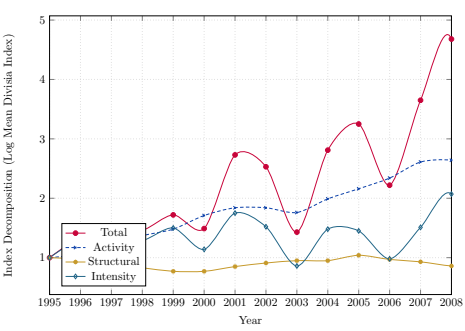

(5.3) Luxembourg

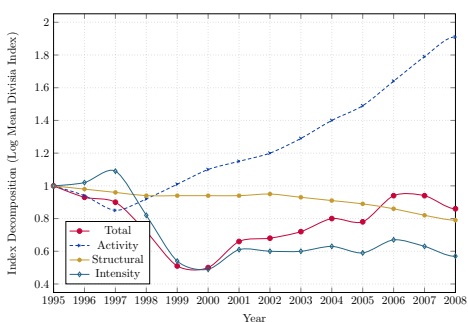

(5.6) Russia

Total material use remained constant or increased only moderately for all best performers from 1995 to 2008. The small economy of Luxembourg is the only exception. The structural effect contributed to falling material use in all of these nations other than Taiwan, where a large shift towards material-intensive sectors could be observed. Structural change in the East Asian country implied an increase of material use of more than 80 per cent relative to 1995. Quantitatively, falling shares of material-intensive sectors reduced material intensities by 12 (Latvia) to 50 (Hun- 
gary) per cent in most best performers. Furthermore, the structural effect did not show large fluctuations, but evolves steadily.

The intensity effect evolved more diversely among the best performers and fluctuations between years are substantially larger than for the structural effect. Luxembourg can serve as an (extreme) example. Generally, smaller countries appear to have more volatile intensity effects than the larger ones. The results also show that the intensity effect reduced material use in most countries (e.g. Czech Republic, Latvia, Poland, Taiwan) from 1995 to 2008 and thus contributed to a stable or even decreasing total material use. We can confirm the findings by Weinzettel and Kovanda (2011) for the Czech Republic. Remarkable are the developments in Hungary, Russia and Taiwan. The intensity effect was positive in Hungary from 1998 to 2005, i.e. sectoral production became more material intensive. This almost compensated the shift towards less material intensive sectors. From 2005 to 2008, the intensity effect returned to a value comparable to 1995 and was the main driver for the total effect. In Russia, the intensity effect reduced material use by 40 percent. Combined with the mild shift towards less material intensive sectors, this compensated for the increase in material use induced by economic growth. The Taiwanese economy reduced its sectoral material intensities by 66 per cent and thus overcompensated the strong structural change towards material-intensive sectors.

All countries in the best performers group exhibited a large economic growth and at least doubled their economic output. However, total material use in all countries beside Luxembourg remained stable or even decreased. We conclude that decoupling of economic growth and material use, i.e. the difference between the activity effect and the total effect was most prevalent in the best performers group. This development results from a combination of structural change and more efficient production technologies.

Medium I Nations in which both gross output and material use grew above the average until 2008 are classified into the medium I group. This group consists mostly of Eastern European economies that benefited from the transition process towards a market economy. Turkey and South Korea as well as, most importantly, China and India are also located in this country group.

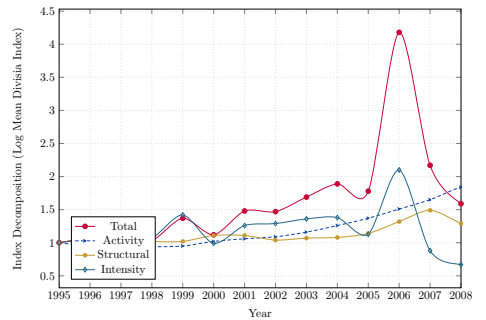

(5.8) Bulgaria

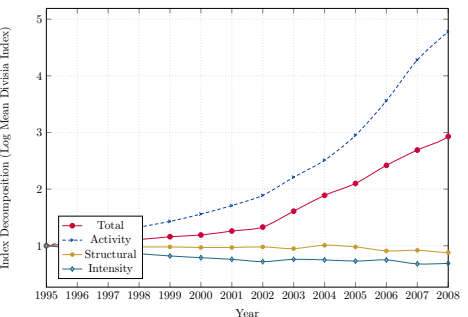

(5.9) China

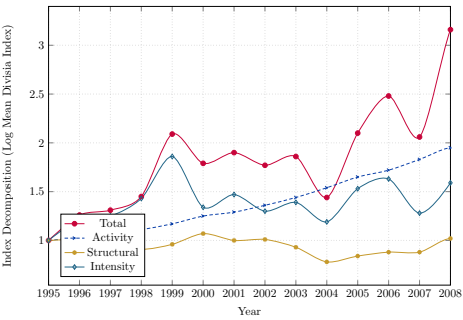

(5.10) Cyprus 


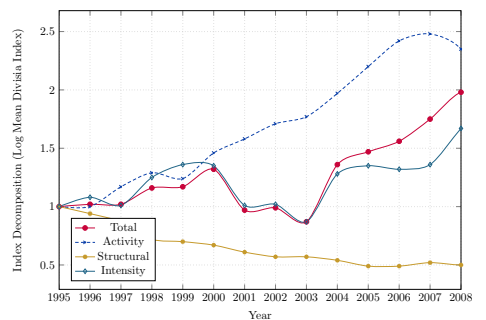

(5.11) Estonia

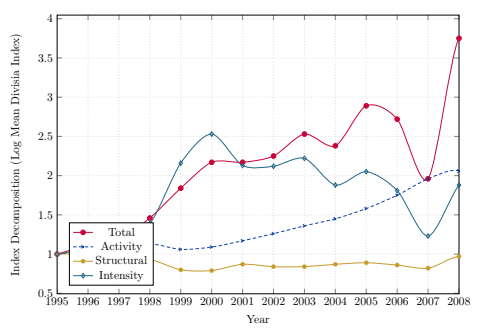

(5.14) Lithuania

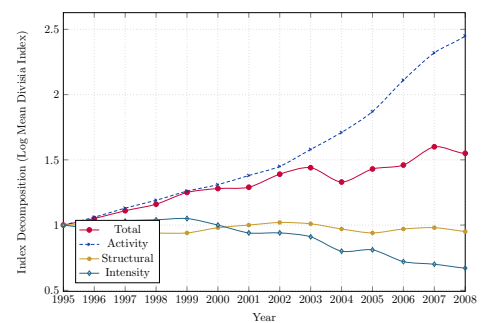

(5.12) India

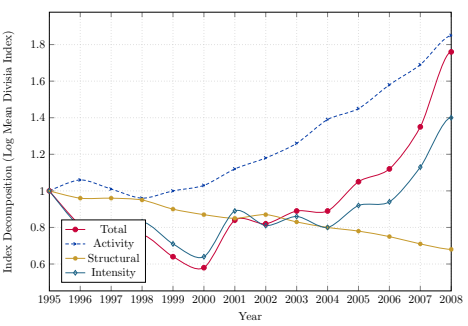

(5.15) Romania

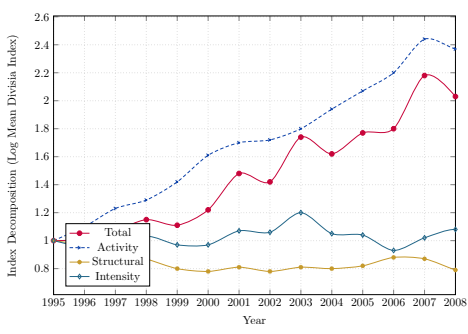

(5.13) Ireland

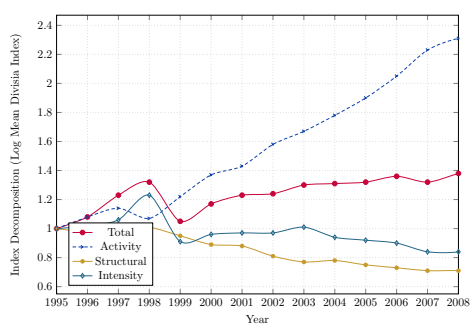

(5.16) South Korea

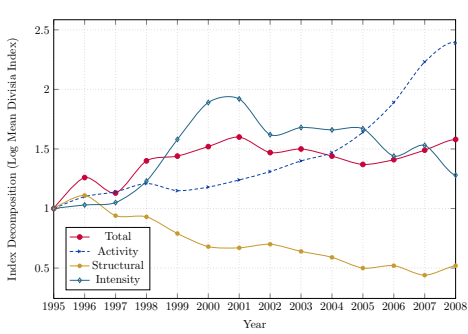

(5.17) Slovakia

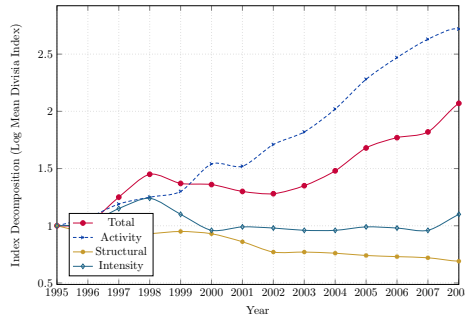

(5.18) Turkey

Total material use increased substantially in nations in the medium I country group between 1995 to 2008 . The structural effect contributed to falling material use in half of the countries, namely Estonia, Ireland, Romania, South Korea, Slovakia and Turkey. The structural effect remained unaltered in China, Cyprus, India and Lithuania and it increased only in Bulgaria.

Among the countries in the medium I country group, Bulgaria, Cyprus, Estonia, Ireland, Lithuania, Romania and Turkey are identified as countries using materials least effectively by European Environment Agency (2010). Our findings match these results. With the exception of Bulgaria, the intensity effect contributed at least mildly to the growing material use in these nations.

The intensity effect emerged differently for the Asian countries. India, South Korea and most importantly China improved their production technologies with respect to material use.

Similarly to the countries in the best performers group, all nations in the medium I group experienced a tremendous economic growth, especially China. They also exhibited an above-average increase in material use, driven by the activity effect in most cases. However, the combination of the structural and the intensity effect moderated the effect for China, India and South Korea. A mild decoupling can be observed for 
these countries. Contrariwise, the total effect even was above the activity effect for the small economies of Cyprus and Lithuania.

The results displayed in figure 55.9 outline China's outstanding importance. The People's Republic exhibited, by far, the strongest activity effect in our sample. Without structural change and the efficiency gains dampening it, Chinese material use would have five-folded from 1995 to 2008. Wang et al.(2012), who investigate China's DMI from 1998 to 2008, find that the use of metallic minerals grows particularly strongly. This coincides with China taking a dominant role in many upstream industries. Take the steel sector as an example. 37.7 per cent of the worldwide crude steel production of 1.3 billion tons took place in the People's Republic in 2008 (World Steel, 2009). In 1995, China accounted for only 4.7 per cent of worldwide crude steel production (IISI, 1996). We can confirm the results of Wang et al. (2012), who found that raising material efficiency in China reduced material use.

Medium II The third country group is denoted medium II. Nations in this group combine a below-average growth in gross output and a below-average growth in material use between 1995 and 2008. With the exception of Mexico and Slovenia, all of these countries are mature industrialized economies.

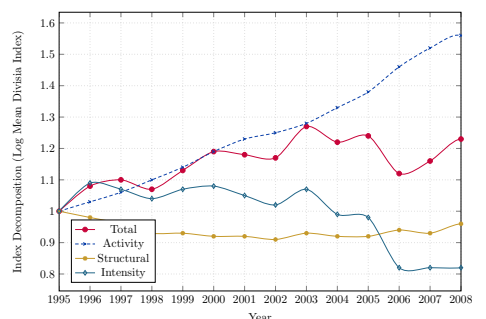

(5.19) Austria

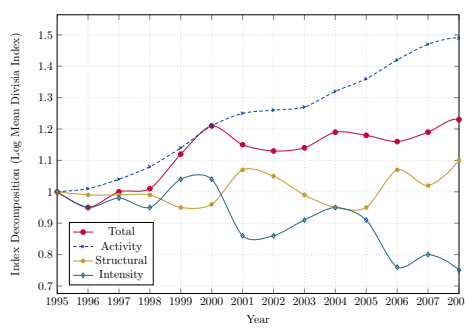

(5.22) France

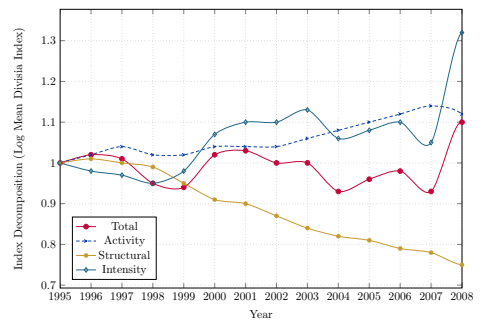

(5.25) Japan

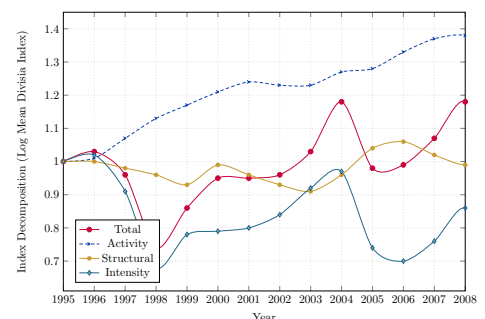

(5.20) Belgium

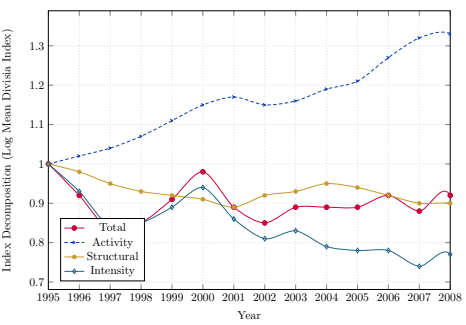

(5.23) Germany

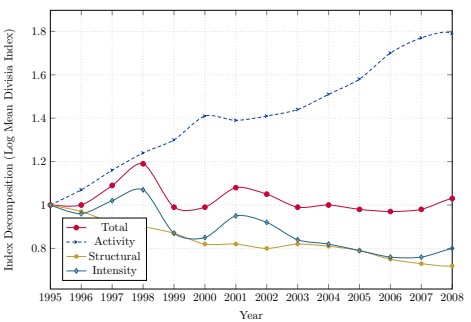

(5.26) Mexico

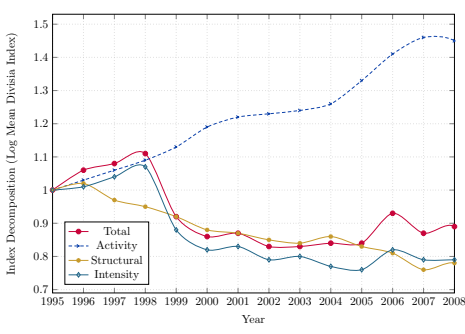

(5.21) Denmark

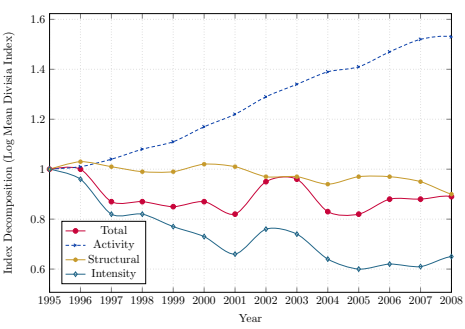

(5.24) Greece

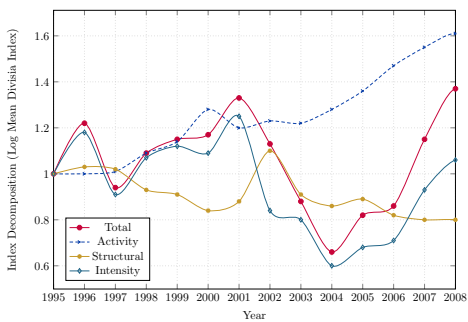

(5.27) Malta 


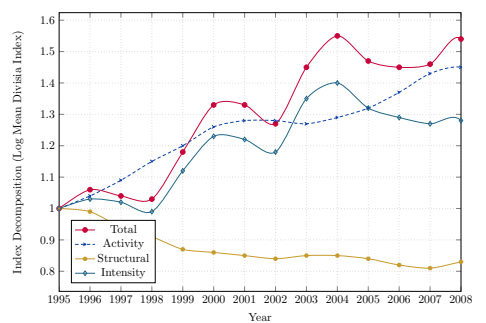

(5.28) Netherlands

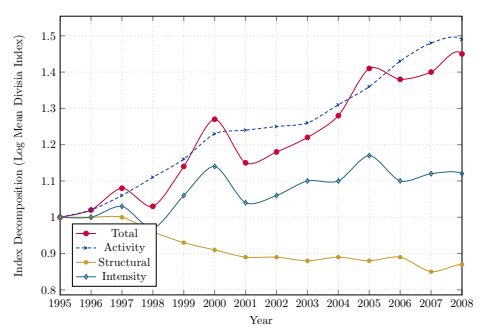

(5.31) Sweden

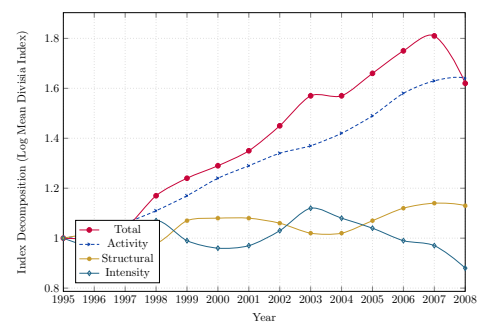

(5.29) Spain

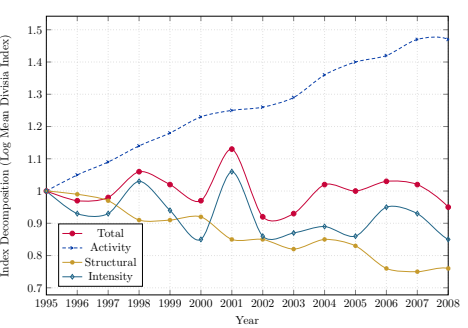

(5.32) United Kingdom

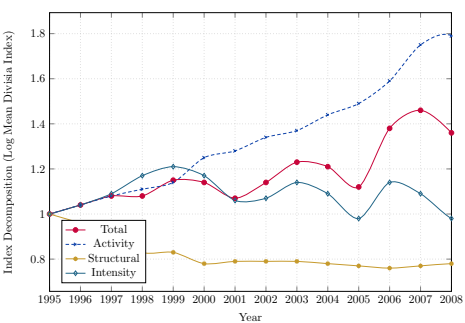

(5.30) Slovenia

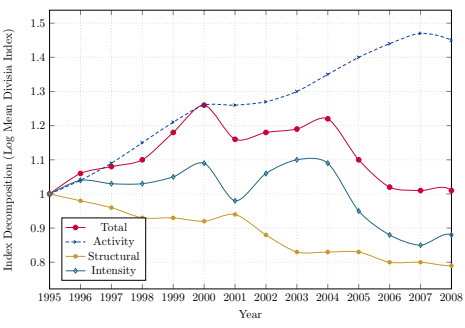

(5.33) United States

Material use remained almost constant in Mexico and the US from 1995 to 2008. It fell slightly in Denmark, Germany, Greece, and the UK. More materials were used, among others, in France, Japan, Spain, and Sweden. Increases were usually in a range of 10 per cent up to 50 per cent.

Economic growth enhanced material use in all medium II countries. Quantitatively, the activity effect ranges from a 10 per cent increase in Japan to 80 per cent in Mexico and Slovenia. In most nations, it augmented material use by around 50 per cent from 1995 to 2008.

Structural change helped reducing the material use in all medium II countries except France and Spain. A falling importance of material-intensive sectors in the economies' composition usually reduced material use by 10 to 20 per cent. Again, the structural effect evolves smoothly over time.

Material intensity decreased in most nations in the medium II group. The intensity effect usually accounts for a 10 to 20 per cent reduction of material use. Growing material intensities can be found, for example, in Japan or the Netherlands.

Japan experienced a shock in material intensity in 2008 , which is plausibly caused by disturbances due to the economic crisis. Up until then, Japan's material use decreased slightly. This development is caused by the intensity and the structural effect, with the latter being more important in quantitative terms. The activity affect was fairly weak in Japan. These results are in line with other studies investigating material use in Japan (Hashimoto et al., 2008; Schandl and West, 2012).

Worst Countries Our final group consists of countries that performed below the unweighted average in gross output and above average in terms of material use. It is a heterogeneous country group, encompassing raw material exporters (Australia, Canada), industrializing nations (Brazil, Indonesia), southern European countries (Italy, Portugal), and Finland as a mature Western European economy. 


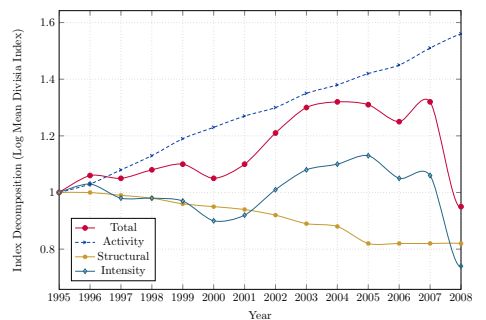

(5.34) Australia

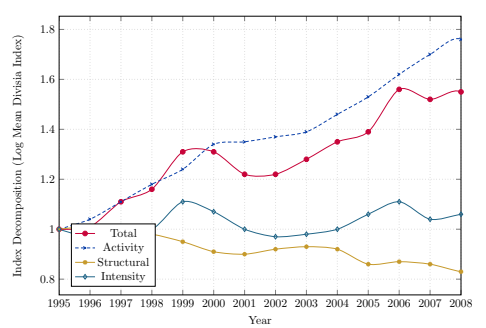

(5.37) Finland

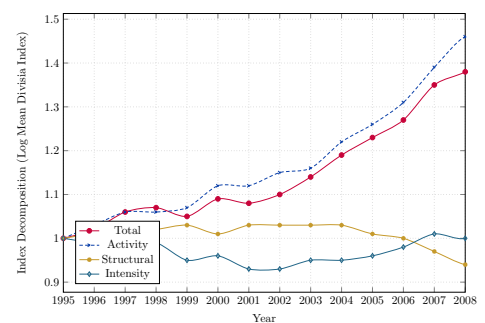

(5.35) Brazil

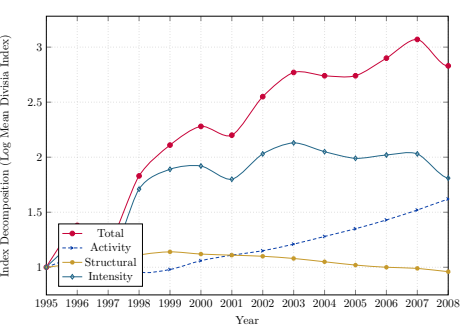

(5.38) Indonesia

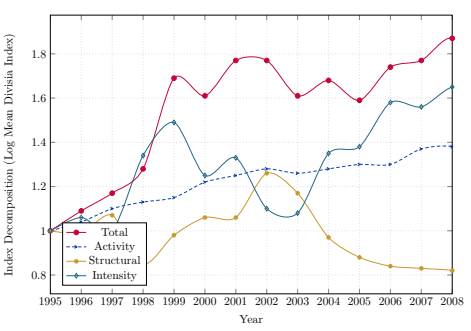

(5.40) Portugal

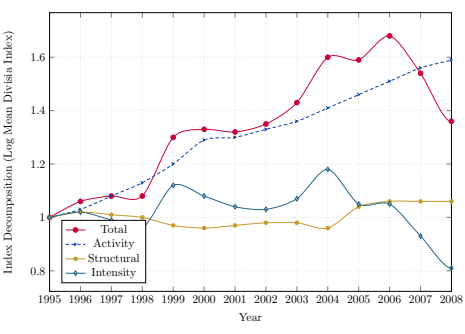

(5.36) Canada

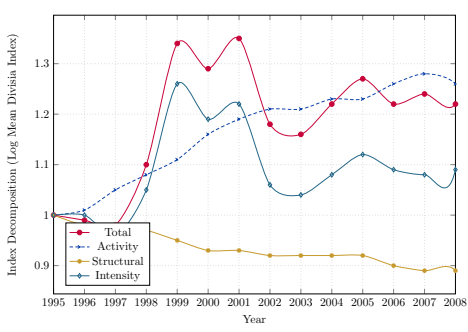

(5.39) Italy

Figure 55.34 depicts the development of a key raw material supplier, Australia. We can confirm the findings by Wood et al. (2009) and Schandl and West (2012) for the total effect. Wood et al. (2009) consider the period between 1975 and 2005 and Schandl and West (2012) between 1970 and 2005. Hence the periodic overlap with our study is 1995 until 2005. As in the other two studies, the total effect is comparable in 1995 and 2005. In our dataset, the total effect declines from 1996 until 2000 and rose again until 2005. Remarkably, the value for the intensity index increased from 0.9 in 2000 up to more than 1.1 in 2005. Wood et al. (2009) disaggregated total material intensity into the components farming, mining, manufacturing and construction. It was observable that material intensity tremendously increased within the mining block. Material intensity within the mining sector increased significantly in Australia.

A strong shock in material intensity occurred between 2007 and 2008 in Australia. In 2007, growing material intensity enhanced material use by 10 per cent relative to 1995. But it lowered material use by 30 per cent in 2008. Note that Canada experienced a similar but less pronounced shock in its intensity effect. Material extraction in Australia grew slightly, from $1,637 \mathrm{kt}$ in 2007 to $1,685 \mathrm{kt}$ in 2008 . At the same time, the agricultural, mining and most material intensive industries expanded their output by 10 to 15 per cent in monetary terms. Neither material extraction nor in- 
dustrial growth is sufficient to explain the shock. The trade patterns of the minerals sector, however, provide an explanation. 39.1 per cent of the Australian mining sector's output were purchased domestically in 2007 . This number fell to 20.0 per cent in 2008. China, on the other hand, accounted for 17.2 per cent of the Australian mining sector's sales in 2007, but for 33.9 per cent in 2008. The Japanese share increased from 17.7 per cent to 23.6 per cent. Canada experienced a similar shock in the share of domestically sold output of the mining sector. It fell from 44.3 per cent in 2007 to 22.0 per cent in 2008. It is likely that the shock in material intensity is driven by distorted trade patterns due to the financial crisis rather than by real gains in material intensity.

For Brazil (figure 55.35), we can confirm the ambivalent trends in terms of the intensity effect. While multi-factor productivity improved in Brazil between 1995 to 2001, it decreased in the period from 2001 to 2009 (Total Economy Database, 2014). This is reflected by the improvement of the intensity effect until 2002. Afterward, the intensity effect rose to a value above the 1995 level. The structural effect developed in an opposite way. The Brazilian economy shifted towards more material-intensive sectors until 2004.

Indonesia is both a developing nation and an important supplier of raw material. WTO (2010) lists Indonesia among the 15 most important exporters of fish, forestry products, and minerals. The Southeast Asian country is, for example, the most important supplier of nickel ores today. While the structural effect was negligible in Indonesia, the activity effect and, in particular, the intensity effect raised Indonesia's material use. Material intensity almost doubled from 1995 to 2008 in Indonesia.

\subsection{Global Results}

In this subsection, we present the results of our four factor decomposition at the global level. Figure 5 highlights the contribution of the activity, the intensity and the two separated structural effects ("within-country" and "between-country") on aggregate material use changes. Our computations are based on equations 12 to 17.

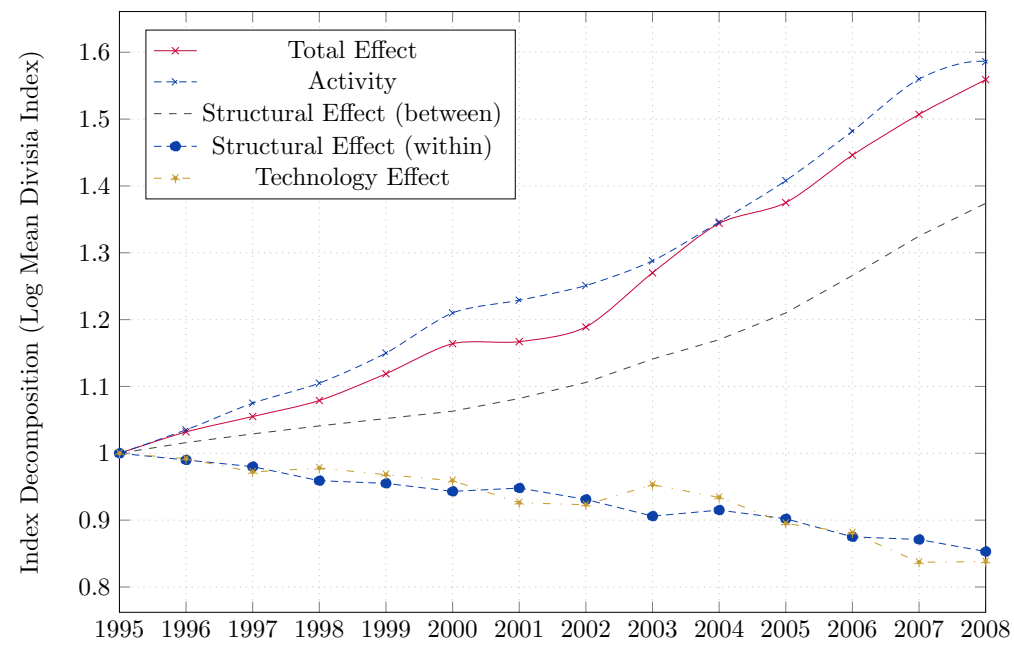

Figure 5: LMDI decomposition of global material intensity 
The decomposition highlights that total material use grew hand in hand with total gross output. Gross output increased by 58.8 per cent and material use by 56.0 per cent between 1995 and 2008. Overall material intensity, i.e. material use divided by gross output, remained almost unaltered between 1995 and 2008. A slight decline between 1995 and 2001 was counteracted by an increase until 2004, resulting in almost an identical global material intensity as in 1995. But what is this development mainly attributable to?

The intensity and the "within-country" structural effect decreased equably to a value of approximately 0.85 in 2008 . The interpretation of the former effect is analogous to that provided in the three factor decomposition, namely less materialintensive production processes due to improved technology. The most rapid declines in the intensity effect occurred between 2003 and 2008. The "within-country" structural effect testifies a shift toward less material-intensive sectors in the countries of our sample. Finally, we observe a steady and tremendous increase in the "betweencountry" structural component which increased by almost 45 per cent. This means that the global economy shifted to countries with a higher material intensity throughout the whole sample period under consideration. China, and to a lesser extent India, account for most of this development. In particular, China more than tripled its gross output share in the global economy, going from 3.8 per cent in 1995 to 11.6 per cent in 2008. In contrast, large developed economies with declining material intensities, such as the US, Japan or many mature European economies, lost relative importance in the global economy.

\section{Conclusions}

This study investigates the drivers of the vastly growing global material use exploiting the World Input-Output Database (WIOD). We define material use as the amount of materials employed directly by sectors and final consumers, both domestic and imported.

Using index decomposition analyses based on the logarithmic mean Divisia index, we disentangle the main drivers of material use on a national and global level: changes caused by economic growth, by structural change in the sectoral composition, and by changes in within-sector material intensity. It is, to our best knowledge, the first Index Decomposition Analysis of material use employing panel data. This approach allows us to investigate both aggregate trends and the heterogeneity of material use.

At a global level, no evidence on dematerialization or notable decoupling of economic growth and material use is found. Economic growth is the most important factor driving the 56 per cent increase in material use. A shift of production towards material intensive countries further contributed to the growing material use from 1995 to 2008 . Within-country structural change towards less material-intensive sectors and growing material efficiency dampened that development. They reduced material use by 15 per cent each.

The country-level analysis reveals substantial heterogeneity. In some nations, such as Russia, material use grows only moderately or even falls in absolute terms. Structural change and efficiency gains counteract increases in material use implied by economic growth. Even in fast growing industrializing nations like China and 
India, efficiency gains decelerate the growth of material use. Industrialized nations exhibit moderately growing material use, explained by structural change.

Our approach allows for a number of extensions, three of which appear to be the most promising. Firstly, evidence suggests that a substantial share of material use in industrializing countries is used to satisfy the demand in developed regions (e.g. Wiedmann et al., 2011; Weinzettel and Kovanda, 2011; Wiebe et al., 2012). Decomposing a panel of material consumption data could contrast the results of this study. Secondly, Steinberger et al. (2010) indicate that drivers of material use differ by type of material. Distinguishing between biomass, fossil fuels, and minerals can provide further insights, but would necessitate disaggregating the mining sector in the WIOD. Thirdly, we identify material efficiencies corrected for structural change. The material efficiency data can be employed to investigate the empirical drivers of macroeconomic material efficiency.

\section{REFERENCES}

Ang, B.W. and Choi, K.-H. (1997): Decomposition of aggregate energy and gas emission intensitites for industry: a refined Divisia index method, in: The Energy Journal, Vol. 18, pp. 59-73.

Ang, B.W., Zhang, F.Q., Choi, K.-H. (1998): Factorizing changes in energy and environmental indicators through decomposition, in: Energy, Vol. 23, pp. 489-495.

Ang, B.W. and Zhang, F.Q. (1999): Inter-regional comparisons of energy-related $\mathrm{CO}_{2}$ emissions using the decomposition technique, in: Energy, Vol. 24, pp. 297-305.

Ang, B.W. and Zhang, F.Q. (2000): A survey of index decomposition analysis in energy and environmental studies, in: Energy, Vol. 25, pp. 1149-1176.

ANG, B.W., LIU, N. (2007): Energy decomposition analysis: IEA model versus other methods, in: Energy Policy, Vol. 35, pp. 1426-1432.

Ang, B.W., Mu, A.R., and Zhou, P. (2010): Accounting frameworks for tracking energy efficiency trends, in: Energy Economics, Vol. 32, pp. 1209-1219.

Behrens, A., Giljum, S., Kovanda, J., and Niza, S. (2007). The material basis of the global economy: Worldwide patterns of natural resource extraction and their implications for sustainable resource use policies. Ecological Economics, 64(2):444453.

Boyd, G.A. and Roop, J.M. (2004): A Note on the Fisher Ideal Index Decomposition for Structural Change in Energy Intensity, in: The Energy Journal, Vol. 25, No. 1, pp. 87-101.

Bruckner, M., Giljum, S., Lutz, C., and Wiebe, K. S. (2012). Materials embodied in international trade - Global material extraction and consumption between 1995 and 2005. Global Environmental Change, 22(3):568-576.

Choi, K.-H., Ang, B.W. (2012): Attribution of changes in Divisia real energy intensity index - An extension to index decomposition analysis, in: Energy Economics, Vol. 34, pp. 171-176. 
Dietzenbacher, E., Los, B., Stehrer, R., Timmer, M. P., de Vries, G. J, 2013. The construction of world input-output tables in the WIOD project. Economic Systems Research 25(1), 71-98.

Dittrich, M. and Bringezu, S. (2010). The physical dimension of international trade: Part 1: Direct global flows between 1962 and 2005. Ecological Economics, 69(9):1838-1847.

http://www.eea.europa.eu/themes/economy/resource-efficiency/resource-efficiencypolicies-country-profiles

$\begin{gathered}\text { European } \\ \text { Environment Agency (2010). Survey of re- } \\ \text { efficiency policies and approaches. }\end{gathered}$
eea.europa.eu/themes/economy/resource-efficiency/
resource-efficiency-policies-country-profiles.

European Environment Agency (2011). Ressource efficiency in Europe - Policies and approaches in 31 EEA member and cooperating countries. EEA Report No 5/2011.

Eurostat (2001). Economy-wide material flow accounts and derived indicators - A methodological guide. Technical report.

Eurostat (2012). Economy-wide material flow accounts compilation guide - revised 26 July 2012. Technical report.

Fischer-Kowalski, M., Krausmann, F., Giljum, S., Lutter, S., Mayer, A., Bringezu, S., Moriguchi, Y., Schütz, H., Schandl, H., and Weisz, H. (2011). Methodology and Indicators of Economy-wide Material Flow Accounting. Journal of Industrial Ecology, 15(6):855-876.

Genty, A., Arto, I. n., and Neuwahl, F. (2012). Final Database of Environmental Satellite Accounts: Technical Report on their Compilation. Technical report.

Giljum, S., Lutz, C., and Jungnitz, A. (2008). The Global Resource Accounting Model (GRAM). A methodological concept paper. Technical report.

Grossman, G. M. and Krueger, A. B. (1991). Environmental Impacts of a North American Free Trade Agreement. NBER Working Paper, No. 3914.

Hashimoto, S., Matsui, S., Matsuno, Y., Nansai, K., Murakami, S., and Moriguchi, Y. (2008). What Factors Have Changed Japanese Resource Productivity? Journal of Industrial Ecology, 12(5-6):657-668.

Hoekstra, R. and van den Bergh, J. C. (2002). Structural Decomposition Analysis of Physical Flows in the Economy. Environmental and Resource Economics, 23(3):357-378.

Hoffrén, J., Luukkanen, J., and Kaivo-oja, J. (2000). Decomposition Analysis of Finnish Material Flows: 1960-1996. Journal of Industrial Ecology, 4(4):105-125.

Ma, C. and Stern, D.I. (2008): China's changing energy intensity trend: A decomposition analysis, in: Energy Economics, Vol. 30, No. 3, pp. 1037-1053. 
Muñoz, P., Giljum, S., and Roca, J. (2009). Global patterns of materials use: A socioeconomic and geophysical analysis. Journal of Industrial Ecology, 13(6):881-897.

Pablo Muñoz, J. and Hubacek, K. (2008). Material implication of Chile's economic growth: Combining material flow accounting (MFA) and structural decomposition analysis (SDA). Ecological Economics, 65(1):136-144.

Schandl, H. and West, J. (2010). Resource use and resource efficiency in the AsiaPacific region. Global Environmental Change, 20(4):636-647.

Schandl, H. and West, J. (2010). Material Flows and Material Productivity in China, Australia, and Japan. Journal of Industrial Ecology, 16(3):352-364.

Schoer, K. (2006). Calculation of direct and indirect material inputs by type of raw material and economic activities. Technical report, Paper presented at the London Group Meeting, 19 - 21 June 2006.

SERI (2013). Global Material Flow Database. Technical report.

Steger, S. and Bleischwitz, R. (2011). Drivers for the use of materials across countries. Journal of Cleaner Production, 19(8):816-826.

Steinberger, J. K., Krausmann, F., and Eisenmenger, N. (2010). Global patterns of materials use: A socioeconomic and geophysical analysis. Ecological Economics, 69(5):1148-1158.

The Conference Board (2014): Total Economy Database, https://www. conference-board.org/data/economydatabase/

Topp, V., Soames, L., Parham, D., and Bloch, H. (2008): Productivity in the Mining Industry: Measurement and Interpretation, in: Productivity Commission Staff Working Paper, http://www.pc.gov.au/_data/assets/pdf_file/0005/84911/ mining-productivity.pdf

Voigt, S., De Cian, E., Schymura, M. and Verdolini, E. (2014): Energy Intensity Developments in 40 Major Economies: Structural Change or Technology Improvement?, in: Energy Economics, Vol. 41, pp. 47-62.

Wang, H., Hashimoto, S., Moriguchi, Y., Yue, Q., and Lu, Z. (2012): Resource Use in Growing China Past Trends, Influence Factors, and Future Demand, in: Journal of Industrial Ecology, Vol. 16, pp. 481-492.

Weinzettel, J. and Kovanda, J. (2011). Structural Decomposition Analysis of Raw Material Consumption. The Case of the Czech Republic. Journal of Industrial Ecology, 15(6):893-907.

Weisz, H., Krausmann, F., Amann, C., Eisenmenger, N., Erb, K.-H., Hubacek, K., and Fischer-Kowalski, M. (2006). The physical economy of the European Union: Cross-country comparison and determinants of material consumption. Ecological Economics, 58(4):676-698. 
Wiebe, K. S., Bruckner, M., Giljum, S., Lutz, C., and Polzin, C. (2012) Carbon and Materials Embodied in the International Trade of Emerging Economies. A Multiregional Input-Output Assessment of Trends Between 1995 and 2005. Journal of Industrial Ecology, 16(4):636-646.

Wiedmann, T., Wilting, H. C., Lenzen, M., Lutter, S., and Palm, V. (2011). Quo Vadis MRIO? Methodological, data and institutional requirements for multi-region inputoutput analysis. Ecological Economics, 70(11):1937-1945.

Wiedmann, T. O., Schandl, H., Lenzen, M., Moran, D., Suh, S., West, J., and Kanemoto, K. (2013). The material footprint of nations. Proceedings of the National Academy of Sciences of the United States of America, pages 1220362110-.

Wood, R., Lenzen, M., and Foran, B. (2009). A Material History of Australia. Journal of Industrial Ecology, 13(6):847-862.

IISI (1996). Steel Statistical Yearbook 1996.

World Steel (2009). Steel Statistical Yearbook 2009.

WTO (2010). World Trade Report 2010. Trade in Natural Resources. 


\section{Appendix A: WIOD SECTORS}

\begin{tabular}{ll}
\hline \hline NACE & WIOD industries \\
\hline AtB & Agriculture, hunting, forestry and fishing \\
C & Mining and quarrying \\
$15 t 16$ & Food, beverages and tobacco \\
$17 t 18$ & Textiles and textile products \\
19 & Leather, leather products and footwear \\
20 & Wood and products of wood and cork \\
21 t22 & Pulp, paper, paper products, printing and publishing \\
23 & Coke, refined petroleum and nuclear fuel \\
24 & Chemicals and chemical products \\
25 & Rubber and plastics \\
26 & Other non-metallic mineral products \\
$27 t 28$ & Basic metals and fabricated metal products \\
29 & Machinery nec \\
$30 t 33$ & Electrical and optical equipment \\
$34 t 35$ & Transport equipment \\
36 t37 & Manufacturing nec, recycling \\
$\mathrm{E}$ & Electricity, gas and water supply \\
$\mathrm{F}$ & Construction \\
50 & Sale, maintenance and repair of motor vehicles \\
51 & Wholesale trade and commission trade \\
52 & Retail trade, except of motor vehicles and motorcycles \\
$\mathrm{H}$ & Hotels and restaurants \\
60 & Inland transport \\
61 & Water transport \\
62 & Air transport \\
63 & Supporting and auxiliary transport activities \\
64 & Post and telecommunications \\
$\mathrm{J}$ & Financial intermediation \\
70 & Real estate activities \\
$71 \mathrm{t} 74$ & Renting of machinery and equipment and other business activities \\
$\mathrm{L}$ & Public administration and defence, social security \\
$\mathrm{M}$ & Education \\
$\mathrm{N}$ & Health and social work \\
$\mathrm{O}$ & Other community, social and personal services \\
\hline \hline
\end{tabular}

Table 1: WIOD industries and definition by NACE

\begin{tabular}{ll}
\hline \hline Materials & Extracting Sector \\
\hline Biomass Animals & AtB \\
Biomass Feed & AtB \\
Biomass Food & AtB \\
Biomass Forestry & AtB \\
Biomass Other & AtB \\
Fossil Coal & $\mathrm{C}$ \\
Fossil Gas & $\mathrm{C}$ \\
Fossil Oil & $\mathrm{C}$ \\
Fossil Other & $\mathrm{C}$ \\
Minerals Construction & $\mathrm{C}$ \\
Minerals Industrial & $\mathrm{C}$ \\
Minerals Metals & $\mathrm{C}$ \\
\hline \hline
\end{tabular}

Table 2: Materials and Extracting Sectors in WIOD 